\section{In vitro Propagation and Plantlet Regeneration from Doritaenopsis Purple Gem 'Ching Hua' Flower Explants}

\author{
Wagner A. Vendrame ${ }^{1}$ and Ian Maguire \\ Tropical Research and Education Center, University of Florida, 18905 SW \\ 280th St., Homestead, FL 33031-3314
}

Virginia S. Carvalho

Departamento de Fitotecnia, Universidade Federal de Viçosa, Viçosa, MG, 36570-000, Brazil

Additional index words. micropropagation, Orchidaceae, orchids, orchid hybrids, TDZ, NAA

Abstract. The effects of four types of explants removed from 10-cm flower stalks of Doritaenopsis Purple Gem 'Ching Hua' (immature apical flower buds, immature lateral flower buds, flower stem nodes, and flower pedicel sections) and combinations of two plant growth regulators [naphthalene acetic acid (NAA) and thidiazuron (TDZ)] on direct in-vitro shoot induction and multiplication were studied. Immature apical flower buds were the only explants that showed induction and multiplication of shoots in vitro. NAA at 5.4 and 10.7 $\mu \mathrm{M}$ combined with either 4.5 or $9.1 \mu \mathrm{M}$ TDZ provided the fastest and greatest percentages of shoot induction (27\% to $40 \%)$ and the greatest numbers of shoot multiplication (111-160 shoots per explant). In vitro-induced shoots were rooted on medium containing 5.4 $\mu \mathrm{M}$ NAA and developed into plantlets with normal vegetative and reproductive morphology. Regenerated plantlets were acclimatized, showing $100 \%$ survival and establishment in greenhouse. Plantlets were grown to maturity and showed normal flower morphology. No floral off-types were observed. The high rates of shoot multiplication obtained offer a means for mass clonal propagation of this and possibly other related Doritaenopsis hybrids.

The production of new and improved orchid hybrids has focused mostly on new flower colors, color patterns, and flower size and number. Over 100,000 commercial orchid hybrids have been registered worldwide to date for either the cut flower or potted plant market. The rapid expansion of the market has increased the interest of growers and customers for new and improved orchids. By 2005, the demand for orchids had placed them in second place among potted floriculture crops in the United States with wholesale revenues estimated at USD 144 million (USDA, 2006). Furthermore, commercial orchid production currently represents $8 \%$ of global floriculture trade, due to the increased demand for orchid cut flowers (Martin and Madassery, 2006).

Doritaenopsis Guillaum. \& Lami is a popular hybrid between Phalaenopsis Blume and Doritis pulcherrima Lindl. and is used as a potted plant or cut flower (Tsukazaki et al., 2000). General micropropagation procedures for Doritaenopsis and Phalaenopsis have been published (Arditti and Ernst, 1993).

Received for publication 15 Feb. 2007. Accepted for publication 18 Apr. 2007.

We thank Dave Baskin for help in obtaining the plant material for this study.

${ }^{1}$ To whom reprint requests should be addressed; e-mail vendrame@ufl.edu on direct in-vitro shoot induction and multiplication in cultures of Doritaenopsis. Plant regeneration, acclimatization, survival, and establishment were also evaluated.

\section{Materials And Methods}

Plant material and explant sterilization. Plants of Doritaenopsis Purple Gem 'Ching Hua' were obtained from McCurdy's Nursery (Homestead, FL). Four types of explants were removed from $10-\mathrm{cm}$ flower stalks (Fig. 1A) from 4 to 7 Oct. 2004: 5.0-mm-long immature apical flower buds (AB), 5.0-mmlong immature lateral flower buds (LB), 10.0 - to $20.0-\mathrm{mm}$-long flower stem nodes (SN), and 5.0- to 10.0-mm-long flower pedicel sections (PS). After removal from flower stalks, explants were washed in distilled water and surface-sterilized with $1 \%$ Alconox (Alconox, New York, NY) solution followed by two rinses in distilled water. Explants were sterilized as follows: 95\% ethanol for $1 \mathrm{~min}$, $1.5 \%$ sodium hypochlorite for 20 min under vacuum and with addition of Tween 20 (3 drops/100 $\mathrm{mL}$ solution), and three rinses in sterilized distilled water. Explants were maintained in sterilized distilled water before initiation of in-vitro cultures.

In vitro shoot induction and multiplication. Explants were placed in $95 \times 15 \mathrm{~mm}$ disposable plastic petri dishes containing a culture medium composed of Gamborg's B5 major salts (Gamborg et al., 1968), MS minor salts (Murashige and Skoog, 1962), and C1 vitamins (Tisserat and Jones, 1999) supplemented with $20 \mathrm{~g} \cdot \mathrm{L}^{-1}$ sucrose, $100 \mathrm{mg} \cdot \mathrm{L}^{-1}$ myo-inositol, $100 \mathrm{mg} \cdot \mathrm{L}^{-1}$ casein hydrolysate, $200 \mathrm{~mL}$ coconut water, and solidified with $6 \mathrm{~g} \cdot \mathrm{L}^{-1}$ Bacto agar (Difco Laboratories, Sparks, MD). The medium $\mathrm{pH}$ was adjusted with either $0.1 \mathrm{~N}$ $\mathrm{HCl}$ or $0.1 \mathrm{~N} \mathrm{NaOH}$ to 5.7 before autoclaving at $121{ }^{\circ} \mathrm{C}$ for $15 \mathrm{~min}$ at $1.2 \mathrm{~kg} \cdot \mathrm{cm}^{-2}$. Multiplication treatments consisted of the same medium described above but supplemented with NAA at 5.4 or $10.7 \mu \mathrm{M}$ combined with TDZ at 2.3, 4.5 , or $9.1 \mu \mathrm{M}$. Cultures were maintained at $27^{\circ} \mathrm{C}$ in the dark for $15 \mathrm{~d}$ for shoot induction followed by $150 \mathrm{~d}$ under an 18 -h photoperiod provided by soft-white fluorescent lamps $(4 \times$ 9 A Philips, Philips Lighting Co., Somerset, NJ) that delivered $80 \mu \mathrm{mol} \cdot \mathrm{m}^{-2} \cdot \mathrm{s}^{-1} P P F$ outside the containers for shoot multiplication.

Rooting and plantlet regeneration. Following induction and multiplication, in vitroinduced shoots were transplanted into Phytotech P700 culture boxes (Phytotechnology Laboratories, Shawnee Mission, KS) containing the same medium as described above for induction supplemented with $5.4 \mu \mathrm{M}$ NAA. Cultures were maintained in a Percival E30B incubator (Percival Scientific, Perry, IA) at $27 \pm 2{ }^{\circ} \mathrm{C}$; an 18 -h photoperiod provided by soft-white fluorescent lamps $(6 \times 9$ A Philips, Philips Lighting Co. $)$ that delivered $80 \mu \mathrm{mol} \cdot \mathrm{m}^{-2} \cdot \mathrm{s}^{-1} P P F$ outside the containers for root development and plantlet regeneration. Cultures were monitored weekly for root induction. Fully regenerated plantlets exhibiting well-developed roots and shoots measuring on average $5.0-6.0 \mathrm{~cm}$ long 

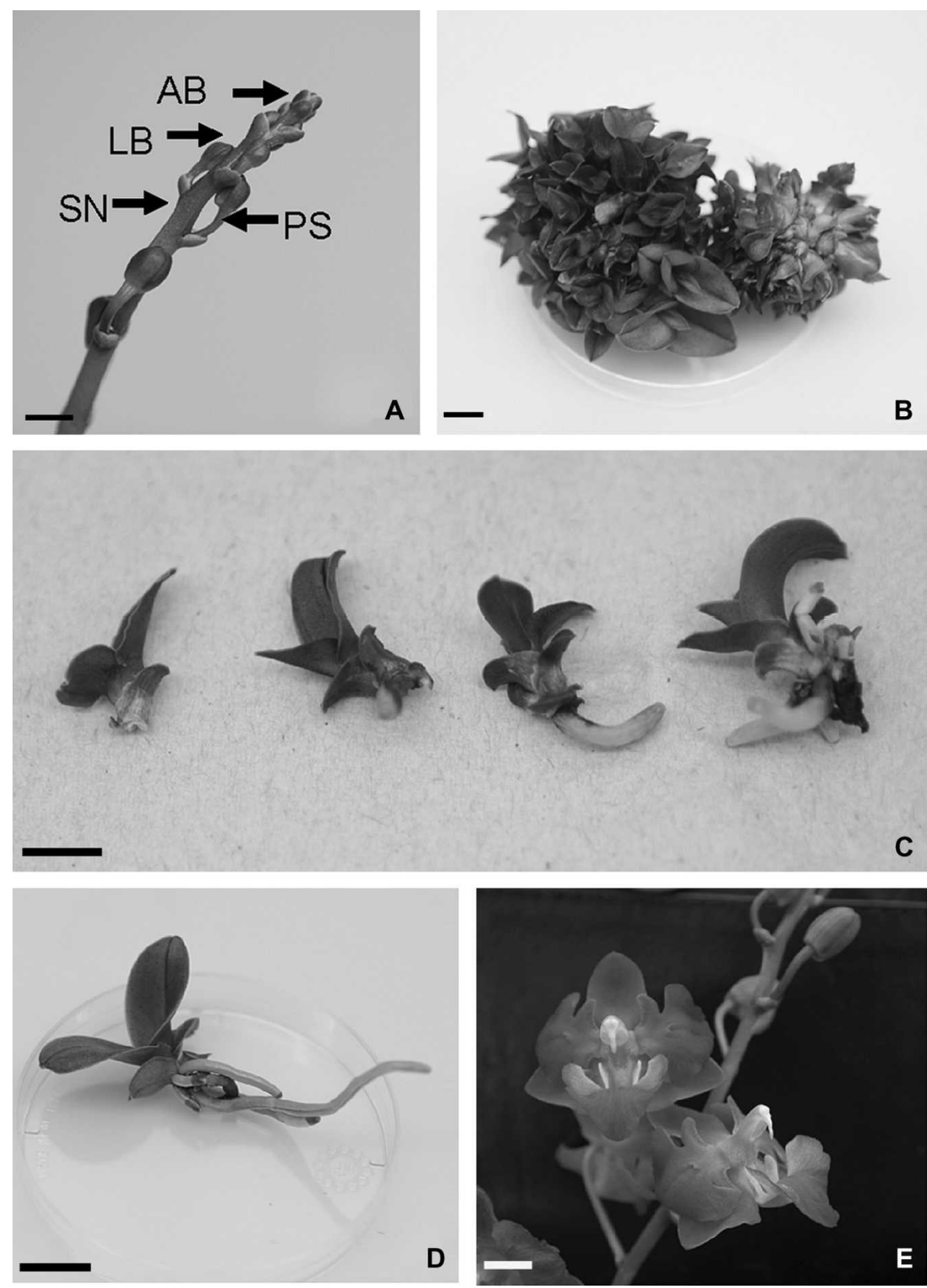

Fig. 1. In vitro propagation and plantlet regeneration from Doritaenopsis Purple Gem 'Ching Hua' flower explants. (A) Four types of explants removed from flower stalks are shown: 5.0-mm-long immature apical flower buds (AB), 5.0-mm-long immature lateral flower buds (LB), 10.0- to 20.0-mm-long flower stem nodes (SN), and 5.0- to 10.0-mm-long flower pedicel sections (PS) $(\mathrm{bar}=10.0 \mathrm{~mm}) .(\mathbf{B})$ Multiple shoot production $(\mathrm{bar}=10.0 \mathrm{~mm}) .(\mathbf{C})$ General in vitro developmental stages from unrooted (left) to rooted (right) shoots (bar $=10.0 \mathrm{~mm})$. (D) Fully developed shoot showing well-developed roots $($ bar $=100 \mathrm{~mm})$. $(\mathbf{E})$ Regenerated plantlet in bloom.

(from root tip to leaf tip) were acclimatized and transferred to greenhouse after $120 \mathrm{~d}$. Plantlets were transplanted to $10-\mathrm{cm}$ pots containing $35 \%$ raw fir bark, $15 \%$ raw pine bark, 15\% coconut fiber (Coco Gro-Brick, OFE International, Miami, FL) $15 \%$ charcoal, and $20 \%$ perlite, and horticultural foam as the substrate. Pots were maintained in greenhouse at average temperatures of $27{ }^{\circ} \mathrm{C}$ high $/ 19{ }^{\circ} \mathrm{C}$ low and an average 220 $\mu \mathrm{mol} \cdot \mathrm{m}^{-2} \cdot \mathrm{s}^{-1} P P F$. Pots were irrigated every other day with a solution of Peters Orchid Food (Spectrum Group, St. Louis) consisting of $30 \%$ total $\mathrm{N}, 10 \% \mathrm{P}_{2} \mathrm{O}_{5}, 10 \% \mathrm{~K}_{2} \mathrm{O}, 0.5 \%$ $\mathrm{Mg}, 0.02 \% \mathrm{~B}, 0.05 \%$ chelated $\mathrm{Cu}, 0.1 \% \mathrm{Fe}$, percentage was calculated based on the number of single explants showing direct shoot formation divided by the total number of explants in each treatment. For percent shoot induction, data were transformed using arcsin transformation before statistical analysis. Experiments were conducted in a completely randomized design and repeated. Analysis of variance (ANOVA; $P \leq 0.05$ ) was performed, and treatment means were compared using Duncan's multiple range test $(P \leq 0.05)$ in the SAS program (SAS Institute, 1989).

\section{Results And Discussion}

In vitro shoot induction and multiplication. Immature lateral flower buds, flower stem nodes, and flower pedicel sections failed to establish in vitro and did not exhibit induction response after $15 \mathrm{~d}$, with subsequent necrosis and death of tissue, or $>40 \%$ contamination after $30 \mathrm{~d}$. Because contamination was observed after $30 \mathrm{~d}$ of culture initiation and on non-responsive cultures, contamination had no direct effect on the failure of cultures to establish but instead was a consequence of tissue decline over time. Immature apical flower buds were the only explants to exhibit induction response, as observed by swelling and enlargement of immature buds 15-30 d after culture initiation, and subsequent direct shoot formation (data not shown). Consequently, treatments were compared for the effects of plant growth regulators on induction and multiplication from $\mathrm{AB}$ explants.

In over $50 \%$ of in-vitro-initiated cultures from $\mathrm{AB}$ explants, the presence of phenolics was observed. Phenolics have been reported to oxidize in the culture medium and become phytotoxic to explants, thus requiring frequent subculturing to fresh medium (Morel, 1974; Ernst, 1994). Specifically in orchids, oxidation of phenolics was reported to account for browning or blackening of explants followed by death (Flamee and Boesman, 1977; Morel, 1974). However, in preliminary studies we observed that the presence of phenolics did not affect the induction, multiplication, and subsequent rooting of shoots developed (W. Vendrame, unpublished data). In the present study, no inhibitory effects by phenolics on shoot induction or multiplication from $\mathrm{AB}$ explants were observed. Explants showed normal development with no visual indication of phytotoxicity, such as browning or blackening, and they multiplied profusely with no degeneration of tissues or death of explants. Multiplied shoots rooted promptly when transferred to rooting medium, and no morphological abnormalities were observed, such as irregular leaf shape and color or abnormal root development and color.

Induction was observed 15-30 d from culture initiation in most treatments for $\mathrm{AB}$ explants, with frequency varying from $4 \%$ to $40 \%$ (Table 1). Shoot organogenesis was observed over a period of $150 \mathrm{~d}$ and varied from 46 to 160 shoots per explant (Table 1). Once initiation was observed, shoots started multiplying, forming clumps with multiple shoots (Fig. 1B). Shoot multiplication was 
Table 1. Percentage of shoot induction (after $30 \mathrm{~d}$ ) and number of shoots per explant (after $150 \mathrm{~d}$ ) from immature apical flower buds of Doritaenopsis with combinations of NAA and TDZ.

\begin{tabular}{cccc}
\hline \multicolumn{2}{c}{ Treatment $(\mu \mathrm{M})$} & $\begin{array}{c}\text { Shoot induction } \\
(\%)^{\mathrm{z}}\end{array}$ & $\begin{array}{c}\text { No. of shoots } \\
\text { per explant }\end{array}$ \\
\cline { 1 - 2 } NAA & TDZ & 0 & 0 \\
0 & 0 & $6.9 \mathrm{~d}^{\mathrm{y}}$ & $67.5 \mathrm{c}$ \\
0 & 2.3 & $4.0 \mathrm{~d}$ & 0 \\
0 & 4.5 & $31.0 \mathrm{~b}$ & $118.5 \mathrm{~b}$ \\
5.4 & 9.1 & $4.0 \mathrm{~d}$ & 0 \\
5.4 & 2.3 & $21.4 \mathrm{c}$ & $62.6 \mathrm{c}$ \\
5.4 & 4.5 & $40.0 \mathrm{a}$ & $160.0 \mathrm{a}$ \\
5.4 & 9.1 & $30.0 \mathrm{~b}$ & $155.3 \mathrm{a}$ \\
10.7 & 0 & $4.6 \mathrm{~d}$ & 0 \\
10.7 & 2.3 & $22.6 \mathrm{c}$ & $46.3 \mathrm{c}$ \\
10.7 & 4.5 & $30.8 \mathrm{~b}$ & $151.3 \mathrm{a}$ \\
10.7 & 9.1 & $26.5 \mathrm{c}$ & $110.7 \mathrm{~b}$ \\
\hline
\end{tabular}

${ }^{\mathrm{z}}$ Data for percent shoot induction were normalized using arcsin transformation.

${ }^{y}$ Mean separation within columns by Duncan's multiple range test at $P \leq 0.05$. Means followed by the same letter are not significantly different.

observed 60-90 d from culture induction and was monitored weekly with a final evaluation at $150 \mathrm{~d}$. There were significant differences for the treatments performed whereby both NAA and TDZ used alone or combined (NAA + TDZ) affected the frequency of shoot induction and the number of shoots produced per explant. The treatment lacking plant growth regulators showed no induction response, and therefore no fresh weight was registered. For all treatments producing shoots, no significant differences were observed in mean fresh weight (9.3-15.6 g) after $150 \mathrm{~d}$ in culture (data not shown). The highest treatments ranged from $30 \%$ to $40 \%$ shoot induction and exhibited the highest number of shoots after $150 \mathrm{~d}$ (Table 1). The highest shoot induction (40\%) was achieved using 5.4 $\mu \mathrm{M} \mathrm{NAA}+4.5$ $\mu_{\mathrm{M}}$ TDZ (Table 1) and differed significantly from other treatments. The use of TDZ alone at $9.1 \mu \mathrm{M}$ and the combinations of $10.7 \mu \mathrm{M}$ $\mathrm{NAA}+4.5 \mu \mathrm{M} \mathrm{TDZ}$ and $5.4 \mu \mathrm{M} \mathrm{NAA}+9.1 \mu \mathrm{M}$ TDZ provided $30 \%-31 \%$ shoot induction and did not differ significantly from each other (Table 1). However, for the number of shoots produced per explant, the combinations of $10.7 \mu_{\mathrm{M}} \mathrm{NAA}+4.5 \mu \mathrm{M}$ TDZ and $5.4 \mu \mathrm{M}$ $\mathrm{NAA}+9.1 \mu \mathrm{M}$ TDZ returned higher numbers of shoots per explant than those produced when using TDZ alone at 9.1 $\mu \mathrm{M}$ (Table 1).

In our study, although the best percentage of shoot induction was only $40 \%$, the number of shoots obtained per explant was higher for all treatments (Table 1) when compared with PLB formation. Studies with PLBs have shown similar or higher rates of induction, but with lower regeneration rates. Park et al. (2002) used thin leaf sections of Doritaenopsis hybrids [Doritaenopsis New Candy $\times$ Doritaenopsis (Mary Anes $\times$ Ever Spring)] to induce PLBs. The highest percentage of PLB formation (72.3\%) resulted in 18 PLBs per explant. In subsequent studies, Park et al. (2003) achieved 47.2\% PLB formation from Doritaenopsis hybrid root tips used as explants, but some PLB formation was callus-mediated and only 2-6 PLBs per explant were observed. Shoot formation ranged from 46 to 160 shoots per explant (Table 1).

In the absence of TDZ, induction percentages were the lowest and no subsequent shoot multiplication was achieved (Table 1). Similarly, Ernst (1994) observed a lack of proliferation in the absence of TDZ for protocorms of Phalaenopsis Dora and Doritaenopsis George Moler induced from flower stem nodes. In that study, TDZ at $11.4 \mu \mathrm{M}$ was the best concentration, producing an average of 10 shoots per node for both hybrids. However, no auxin was used. Using Doritaenopsis hybrids, Park et al. (2002, 2003) produced PLBs from thin leaf sections and root tip explants using 9.1 and $2.3 \mu \mathrm{M}$ TDZ alone, respectively. In our study, immature apical flower buds produced the largest number of shoots at concentrations of $9.1 \mu \mathrm{M}$ TDZ alone, while reduced numbers of shoots were observed with $2.3 \mu \mathrm{M}$ TDZ alone (Table 1). In contrast, when an auxin (NAA) was used alone, no shoot formation was observed (Table 1).

Chen and Chang (2004) observed that in the presence of 4.5 and $13.6 \mu \mathrm{M}$ TDZ, NAA significantly decreased somatic embryo formation from seed-derived protocorms of Phalaenopsis amabilis var. Formosa Shimadzu. However, in our study NAA at 5.4 or $10.7 \mu \mathrm{M}$ significantly increased the number of shoots formed per explant when in the presence of 4.5 or $9.2 \mu \mathrm{M}$ of TDZ. TDZ has been demonstrated to successfully induce shoot organogenesis in different orchid species (Chen and Chang, 2001; Nayak et al., 1997). In this study, the effectiveness of TDZ to induce shoot organogenesis from immature apical flower buds of Doritaenopsis Purple Gem 'Ching Hua' was addressed through the high number of shoots obtained when TDZ was used alone at 9.1 $\mu \mathrm{M}$. Furthermore, when TDZ was combined with NAA, an efficient means to induce multiple shoots in vitro was observed, as indicated by the higher number of shoots developed per explant as compared with studies examining PLB formation.

Rooting and plantlet regeneration. Following shoot multiplication, shoots were isolated and transferred to a rooting medium, where $100 \%$ of in vitro-induced shoots rooted and regenerated plantlets (data not shown). In some cases, roots formed in the multiplication medium, facilitating the rooting process and producing healthy plantlets. Despite the presence of phenolics in culture, no abnormalities or detrimental effects were observed and shoots developed healthy roots, thus regenerating into plantlets with normal vegetative and reproductive morphology. General developmental stages from unrooted to rooted shoots are shown in Fig. 1C. Fully developed shoots containing well-developed roots (Fig. 1D) were transferred to $10-\mathrm{cm}$ pots containing potting mix and acclimatized under greenhouse conditions. Plantlets were grown to maturity within $8-10$ months and showed normal peloric flower morphology (Fig. 1E). No floral off-types were observed. Regenerated plantlets showed $100 \%$ survival and establishment in greenhouse.
We have demonstrated an efficient means for in vitro clonal propagation and plant regeneration from immature apical flower buds of Doritaenopsis Purple Gem 'Ching Hua' using direct in vitro shoot organogenesis. The high rates of shoot multiplication obtained are essential for the large-scale commercial production of orchids and offer a means for mass clonal propagation of this and possibly other related Doritaenopsis hybrids.

\section{Literature Cited}

Arditti, J. and R. Ernst. 1993. Micropropagation of orchids. Wiley, New York.

Chen, J.T. and W.C. Chang. 2001. Effects of auxins and cytokinins on direct somatic embryogenesis from leaf explants of Oncidium 'Gower Ramsey'. Plant Growth Regulat. 34:229-232.

Chen, J.T. and W.C. Chang. 2004. Induction of repetitive embryogenesis from seed-derived protocorms of Phalaenopsis amabilis var. Formosa Shimadzu. In Vitro Cell. Dev. Biol. Plant 40:290-293.

Ernst, R. 1994. Effects of thidiazuron on in vitro propagation of Phalaenopsis and Doritaenopsis (Orchidaceae). Plant Cell Tissue Org. Cult. 39:273-275

Flamee, M. and G. Boesman. 1977. Clonal multiplication of Phalaenopsis hybrids by means of sections of flower stalks. Med. Fac. Landbouw. Rijksuniv. Ghent. 42:1865-1868.

Gamborg, O.L., R.A. Miller, and K. Ojima. 1968. Nutrient requirements of suspension cultures of soybean root cells. Exp. Cell Res. 50:151-158.

Lin, C.C. 1986. In vitro culture of flower stalk internodes of Phalaenopsis and Doritaenopsis. Lindleyana 1(3):158-163.

Martin, K.P. and J. Madassery. 2006. Rapid in vitro propagation of Dendrobium hybrids through direct shoot formation from foliar explants, and protocorm-like bodies. Sci. Hort. 108:95-99.

Morel, G. 1974. Clonal multiplication of orchids. In: C.L. Withner (ed.). The orchids: scientific studies. Wiley, New York.

Murashige, T. and F. Skoog. 1962. A revised medium for rapid growth and bioassays with tobacco tissue cultures. Physiol. Plant. 15:473-497.

Nayak, N.R., S. Patnaik, and R.P. Rath. 1997. Direct shoot regeneration from foliar explants of epiphytic orchid Acampae praemorsa (Roxb.) Blatter and McCann. Plant Cell Rep. 16:583-586.

Park, S.Y., E.C. Yeung, D. Chakrabarty, and K.Y. Paek. 2002. An efficient direct induction of protocorm-like bodies from leaf subepidermal cells of Doritaenopsis hybrid using thin-section culture. Plant Cell Rep. 21:46-51.

Park, S.Y., H.N. Murthy, and K.Y. Paek. 2003. Protocorm-like body induction and subsequent plant regeneration from root tips cultures of Doritaenopsis. Plant Sci. 164:919-923.

SAS Institute. 1989. SAS/STAT user's guide, version 6. 4th ed. SAS Institute, Cary, NC.

Tisserat, B. and D. Jones. 1999. Clonal propagation of orchids. Plant Cell Cult. Protocols 111:127-134.

Tokuhara, K. and M. Mii. 1993. Micropropagation of Phalaenopsis and Doritaenopsis by culturing shoot tips of flower stalk buds. Plant Cell Rep. 13:7-11.

Tsukazaki, H., M. Mii, K. Tokuhara, and K. Ishikawa. 2000. Cryopreservation of Doritaenopsis suspension culture by vitrification. Plant Cell Rep. 19:1160-1164.

USDA. 2006. Floriculture crops-2005 summary. Natl. Agr. Stat. Serv., U.S. Dept. of Agriculture, Washington, DC. 